\title{
Bed-load transport: From the beginning into the future
}

\author{
Willi H. Hager ${ }^{1}{ }^{*}$ \\ ${ }^{1}$ Laboratory of Hydraulics, Hydrology and Glaciology VAW, ETH Zurich, CH-8093 Zürich, \\ Switzerland
}

\begin{abstract}
This research addresses bed-load transport in the fluvial environment. Based on the current knowledge, it is first noted that this problem is by far not solved. The eminent questions ask for a large experimental campaign by which the basic issues are solved first, and then expanded to more challenging topics relating to questions not included in the first stage involving uniform water and sediment flows. A number of currently available experimental techniques is mentioned by which a highquality laboratory experimentation should be feasible. Next, the effects of various fundamental transport parameters should be cleared using both systematic experimentation and data analyses. An improved bed-load transport equation should be established first, by which the current tools are replaced to produce better agreement with prototype data. The role of computational hydraulics is also highlighted, to apply results to natural rivers. Froude similitude should be carefully applied so that the laboratory data can safely be transferred to prototype conditions, if the limitations are respected.
\end{abstract}

\section{Introduction}

Sediment transport is commonly subdivided into bed-load and suspended load. The following deals exclusively with bed-load, i.e. the transport mode of sediment close to the bed. The hydraulic features of the two-phase problem involving rigid particles and water has received comparatively late interest in hydraulic and fluvial engineering, because its physical description is far from being evident. Despite the many incidents all through the ages, notably during river low- and high-flows, with consequences of riverbed degradation and aggradation, loss of agricultural land or of lives, among many other issues, the first account on bed-load transport was given by Du Boys only in 1879, i.e. nearly 140 years ago. His theoretical model produced a non-homogeneous equation for the unit bed-load transport $q_{s}$ involving the drag force $S=\rho_{s} g h J$, with $\rho_{s}$ as sediment mass density, $g$ as the gravity acceleration, $h$ as the flow depth in a rectangular channel, $J$ as the free surface slope, and the mass density difference between sediment and water as $\Delta \rho=\rho_{s} /\left(\rho_{s}-\rho\right)$. The equation further includes the difference between the drag force $S$ and the entrainment drag force $S_{e}$, which depends according to [1] on $\Delta \rho$, the square of the average flow velocity, and a sediment shape number [2]. In his PhD thesis, [1] verified the concept of Du Boys, finding general agreement

\footnotetext{
*Corresponding author: hager@vaw.baug.ethz.ch
} 
with his relatively crude test data. This was the first great success in bed-load transport, which was reduced in terms of expansion at the time by World War I. Except for [3], who conducted a large number of bed-load tests, further test series were designed only in the 1920s mainly by Austrians, including Schaffernak, Kurzmann, and Schoklitsch [2]. During the early 1930s, the Austrians Ehrenberger and Mühlhofer conducted first successful prototype observations, by which additional insight into the complex problem was gained. [4] and [5] published their sediment transport formulas in the same year. Both contain the sediment diameter $d$, the free surface slope and the difference $q-q_{e}$, with $q_{e}$ as the unit width entrainment discharge and $q$ as the unit width water discharge, depending in Schoklitsch's formulation on $d / J^{4 / 3}$, whereas Meyer-Peter et al. relate $q_{e}$ to $(d / J)^{3 / 2}$.

From the mid-1930s, Germany took over the main role in the development of these issues, but shortly later had to stop because of the dawn of World War II. This was the moment for the Americans to take over the lead, with Lorenz Straub (1901-1963), Hans Kramer (18941957), Morrough P. O’Brien (1902-1988), Albert Shields (1908-1974), or Hunter Rouse (1906-1996) as the main exponents until 1945 [2]. The USA kept leadership until around the mid-1970s.

Looking back into this era, it must be noted that few experimental advances have been conducted in the past 40 years. During the 1960s and early 1970s, the main journal dealing with this topic, namely the Journal of the Hydraulics Division, ASCE, included in almost each issue a new paper in this field. These findings served as a valuable data basis for the exploration of further details, but novel, large experimental campaigns are hardly noted. It appears that the interest into this exciting field of hydraulics was lost, despite the knowledge was not at all sufficient to design, execute and maintain fluvial rivers in terms of bed-load transport as would have been expected. Similar issues occurred to hydraulic structures, because the common thought was to initiate researches in other fields, as in environmental hydraulics, chemical engineering or in industrial flows. Whereas hydraulic engineering has seen a great revival since around 2000, this return in bed-load transport is currently not yet reached, at least according to this author. The considerations presented below would like to forward some reasons for a full reconsideration of bed-load transport, given the many questions waiting to be solved.

When looking at the recently available guidelines to solve questions of bed-load transport, only few definite answers are given. [6], one of the leading Americans in this research field, came to the conclusion that no sediment transport formula would result in anything better than a rough estimate. [7] summarized their conclusions in five statements:

- Only complete data sets serve as a reliable basis of comparison

- As to the total sediment load, the formula of [8] performed best for selected US data, whereas that of [9] was best among 15 selected formulas

- Meyer-Peter and Müller's, and Shields' formulas tend to overpredict the flume data, whereas these of Bagnold, Yalin, or Smart tend to the opposite

- According to [10], not any sediment transport formula is able to correctly predict the transport for all ranges of parameters

- According to [11], the formula of [12] performs best for 40 field and 225 flume tests. A detailed analysis provides [13].

[14] considered three formulas, namely that of [4], [15], and of [16]. Based on the latter formulation, the laboratory data of Gilbert and Meyer-Peter and Müller yield almost identical results for uniform sediment. It is therefore concluded that Einstein's formulation applies best for both uniform and non-uniform sediments if the sediment diameter is limited to above $0.7 \mathrm{~mm}$, and bottom slopes vary from 0.3 to $2 \%$. It is further stated that sediment mixtures can be considered as a uniform sediment matrix based on the mixture diameter $d_{35}$. In concluding, it is stated [14]: 
- Of all the many formulas proposed, none is able to translate the complexity of the phenomena into a nearly perfect result

- All formulas should only be applied in the proposed limitation ranges of parameters involved

- Most of the formulas were established based on laboratory tests, but are normally applied to prototype rivers, involving additional complexities

- [17] have compared the results of nearly 1,000 test data by which 19 different formulas were proposed. The performance of their own formula was best, followed by Einstein's.

- It should be noted that each formula provides a result, yet none is sufficiently accurate. All formulas thus provide a certain guide for engineers.

[18] lists a total of 13 transport formulas. No direct comparison with test data is provided, however. It is stated that field observations provide the best information for both developing and testing new formulations. It is further admitted that these relations for the 2D environment provide an even larger challenge, and few information is currently available. Garcia finally states that to predict morphological changes in rivers, new technologies are necessary so that sediment transport should be given priority in sediment transport research. [19] mentions three formulas, namely these of Du Boys, of [15] simplified by [20], and of Einstein and Brown [21]. No recommendation relative to their applications is made, however. [22] lists numerous formulas but hardly addressed the issue on what to select for a particular problem.

Given the above current state of knowledge, it should be evident that new research campaigns in bed-load transport need to be initiated, to understand its basics, to limit its applications, and to generate adequate information to solve, at least on the basis of fluvial engineers, the most important questions. It appears also that currently so much isolated knowledge is available that only few experts are able to understand the essence. Keen and enthusiastic researchers need to attack a problem that is far from being solved. Further, it should be recognized that this fluvial problem is of great relevance for the entire planet, to understand the role of rivers on it. The main message of this paper should therefore be: Why not reconsider systematic research in the spectacular field of bed-load transport?

\section{Future Research Agenda}

Three particular aids are currently available to find an engineering solution to the bed-load problem: (1) Excellent hydraulic laboratory techniques, (2) Systematic data analyses for large data bases, and (3) Interaction between researchers and practitioners to find a common way of best representation of the final output. These three issues are detailed below.

A laboratory test campaign on $2 \mathrm{D}$ bed-load transport poses no particular problems. Two fundamental approaches were considered in the past, which still apply for future experimentation: (1) both uniform water and sediment flows as the test basis, and (2) pure erosion flow (Fig. 1). Tests were usually conducted in rectangular, not too wide channels to inhibit 3D flow structures. All tests involve well-defined test parameters relating to the sediment size, the mixture characteristics and sediment shape, as well as the water discharge. Tests (1) are based on a constant bed slope and designed so that the bed-load transport remains also uniform, i.e. the sediment bed is kept parallel to the water surface, or the flow depth remains constant. The resulting flow thus is based on uniform flow conditions for both the sediment and water phases, representing the simplest test set-up as the basis of bed-load transport. Note that nearly all proposed formulas relate exclusively to this simplified, but important fundamental test procedure. Tests may be of long duration, because the eroded sediment has to be added at the intake, yet the required quantity of sediment discharge at test start is unknown. The entire process thus is asymptotic. 
Tests (2) are much faster accomplished. Sediment is placed before test start as a wedge into the channel, with the addition of a nearly horizontal reach close to the channel intake, allowing for additional erosion once the test advances. This wedge is progressively eroded, finally resulting in a sediment matrix of nearly constant slope. Compared to Tests (1), no sediment must be fed at the channel intake, possibly perturbing the test advance due to the impact of sediment particles onto the water surface. Based on methods discussed below, the sediment (subscript $s$ ) surface $z_{s}(x, t)$ is known at each time, allowing to detract the relevant test results.

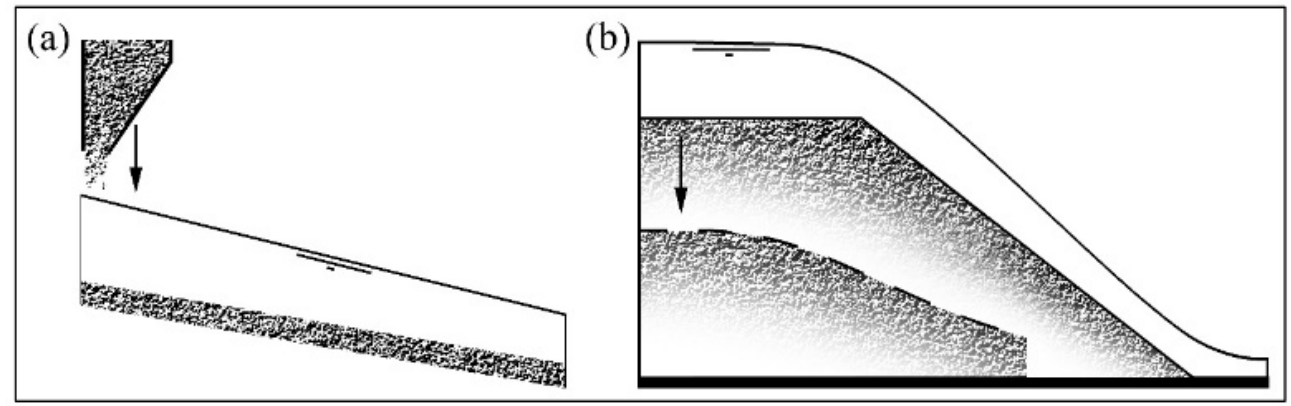

Figure 1. Basic procedure for laboratory designed tests relating to bed-load experimentation (a) Test type (1) involving uniform flows for both sediment and water, (b) Test type 2 starting with a sediment wedge extended into the intake portion, which is eventually eroded by the constant water discharge

Both fundamental test procedures (1) and (2) should be regarded as complimentary, because none itself is able to give a full answer to the problem. As stated by [2], a particular issue is considered important, namely test initiation. The author has often noted that test initiation started with zero flow depth, by which the test set-up is disturbed right from test start. To avoid involuntary erosion at test start, the entire test channel should be submerged from the tail-water, water discharge then set to test conditions, and only then, the tailwater should be lowered to test conditions.

To accomplish systematic and accurate research in bed-load transport, test conditions should be limited to Froude scaling. This implies that certain limitations have to be accepted, so that no significant scale effects affect the final results. These include:

- Minimum sediment size of roughly $1 \mathrm{~mm}$, to exclude effects of apparent cohesion by which viscous effects may become important

- Minimum flow depth of roughly $50 \mathrm{~mm}$ to exclude flows of too small depth by which surface tension effects may become important, and photogrammetric methods become not enough accurate

- Minimum Reynolds numbers, i.e. average velocities, well above the laminar flow limit; typically a factor of 10 is considered, so that viscous effects remain absent

- Water and sediment quality, to allow for a clean two-phase flow, for which optical access is guaranteed.

The governing parameters of bed-load transport are established for a long time. These include the relative unit bed-load transport rate $\phi=q_{s} /\left[\rho\left(R g d_{m}{ }^{3}\right)^{1 / 2}\right]$ and the densimetric grain Froude number $1 / \psi=V_{*}^{2} /\left(R g d_{m}\right)=h J /\left(R d_{m}\right)$ with $V_{*}=(g h J)^{1 / 2}$ as shear-velocity, $d_{m}$ as the average sediment size, and $R=\left[\left(\rho_{s}-\rho\right) / \rho\right]$ as the density difference between the two phases sediment and water. Additional parameters may be added to these two fundamental variables, depending on the effects investigated. A number of these will be discussed below.

Last, the results obtained from these systematic data analyses should be discussed with colleagues, who will be potential appliers of what was obtained. These do not only include river engineers, but biologists, environmental engineers, water management experts, or earth 
scientists will also be interested to discuss the major findings of this hydraulic problem. Their input could also be important in the practical application of the findings to rivers in a certain catchment area. This point was possibly often not sufficiently considered in the past, so that the results remained isolated in the academic circles, yet have hardly found their way to engineering practice. If the planned research project is of a certain size, the main actors should also be ready to publish their results not only in top journals, but possibly also invite interested colleagues, authorities, and practicing engineers dealing with the problem to workshops, during which the major results are critically assessed by all participants, to allow for a wide acceptance of the findings.

\section{Novel Hydraulic Experimentation}

The main motivation to start this research was the author's feeling that few systematic test campaigns have been conducted in the past decades, despite the limited knowledge in a fundamental field of river engineering. During these years, the experimental techniques have dramatically improved, so that a new and fresh approach to the problem will be feasible. The following points can be mentioned [2]:

- Artificial sediment of any density and shape, removing concerns relating to these effects. Note that plastic grains do not undergo abrasion, and the flow remains much cleaner than with fluvial sediment, allowing for easy optical access during bed-load transport;

- Videotechnics by which a test is easily recorded and reviewed after test completion. As noted, clean material is required to allow for good optical access to the water flow and the sediment layer below it;

- Photogrammetry to visualize the temporal advances of bed-load surfaces subjected by the water flow. By projecting a grid pattern onto it, their evolution allows for capturing topographical changes. Note that this system gives an instantaneous surface mapping typically from 1 to $10 \mathrm{~m}^{2}$, depending on the resolution;

- Laser scanning similar to photogrammetry but resulting in non-instantaneous topographical data thus applying for slowly varied processes. Note that the latter two methods both are limited in water flow depths, depending on the water quality;

- $\quad P I V$-technique to explore velocity fields with and without the presence of bed-load transport under otherwise identical conditions, and to determine flow parameters from the resulting velocity profiles;

- Wind tunnel by which the fluid component is suppressed so that only air and sediment are involved. This simplification appears relevant with limitations in water quality or water flow depth. Note the relevance of bed-load transport in sand-wind, or snow-wind flows;

- Concept of densimetric Froude number, by which sediment smaller than, say, $1 \mathrm{~mm}$ is replaced by larger particles of smaller density. It only applies, however, if the Froude number expressed as average velocity divided by the square root of gravity acceleration times flow depth is much smaller than unity, so that dynamic effects remain absent; and

- Concept of unit stream power, defined as the product of fluid density times gravity acceleration times unit discharge times bottom slope. Bagnold applied it successfully in the mid-1960s to bed-load transport, and it has been effectively used to predict the evolution of riverbeds, river migration and bed-load transport.

All these techniques are currently commercially available, so that laboratories interested in pursuing these tests can acquire the systems necessary for high-quality experimentation. Note that the cost of certain components is high, so that a research background has to be defined. 
What topics should be considered in a first step? The ultimate purpose should be the definition of a more or less accurate (to be defined) bed-load transport formula able to reproduce the main features. To finally achieve this challenging goal, laboratory research under the mentioned limitations should be conducted. The major parameters to be studied during the first step are, according to the present author, the effects of:

- Sediment size

- Sediment mixture

- Bed slope

- Flume width

- Wall roughness

- Water discharge

In a second step, once these basic issues are cleared, the issues to be addressed are:

- Bottom shape (increasing or decreasing bed slopes)

- Side slope (from triangular to trapezoidal

- Expansion or contraction in plan

- Morphological elements as bars

- Unsteady flow features due to temporal variations of discharge or flow depth

- Change of sediment characteristics during a test

Many more set-ups are possible, yet these can only be based on a sound knowledge formulated after the fundamental tests have been analyzed. It should also be mentioned that computational hydraulics should be considered essential in a large test campaign, to advance the knowledge also in this second direction of approach, to finally present a hybrid method of attack to the bed-load transport problem.

In addition, a supplementary input was provided by [23] mainly in terms of the statistical description of sediment transport, while [24] investigated so-called bed-load sheets as a consequence of grain sorting. [25] conducted experimental research on the dynamics of bed particles sheared by Couette flow to determine the distributions of particle velocities, durations and lengths of particle saltation flights. The ripple length on a granular bed sheared by a liquid was selected and described by [26]. Bed load transport in turbulent flow at grain scale was studied by [27]. Trajectories of the moving particles and their velocities and flight durations were recorded. In a series of four papers, [28] present a probabilistic description of bed load transport. Another description of the statistical properties of bedload transport is provided by [29]. Note that all these recent additions do not directly respond to the author's proposal to present a novel bed-load transport formula for the practicing fluvial engineering community.

\section{Conclusions}

Fluvial bed-load transport counts to the fundamental problems of river engineering. Despite of numerous experimental studies, the current knowledge is far away from what should be available, to solve the most urgent problems in this field. Based on a review of current textbooks and guidelines, it is found that none of the available formulations dealing with bedload processes allows for a more or less adequate solution in practice. None of these texts gives a clear recommendation as to what formula should be applied under certain conditions imaging the governing parameters of the problem considered.

Given this state, a novel and fresh large research campaign should be initiated involving the currently available advanced experimental methods, to generate a systematic database by which an improved bed-load transport equation is presented allowing for the solution of the fundamental problems first, and then detailing further aspects of this highly fascinating issue. 


\section{References}

[1] A. Schoklitsch, Über Schleppkraft und Geschiebebewegung (On drag force and bed-load transport) (Engelmann, Leipzig, 1914)

[2] W.H. Hager, J. Hydraulic Research (to be published 2018)

[3] G.K. Gilbert, Transportation of debris by running water. US Geological Survey, Professional Paper 86, (Government Printing, Washington DC 1914)

[4] A. Schoklitsch, Wasserkraft und Wasserwirtschaft, 29(4), 37-43 (1934)

[5] E. Meyer-Peter, H. Favre, H.A. Einstein, Schweizerische Bauzeitung, 103(13), 147-150 (1934)

[6] V. Vanoni, ed., Sedimentation engineering (ASCE, New York, 1975)

[7] B. Przedwojski, R. Blazejewski, K.W. Pilarczyk, River training techniques: Fundamentals, design and application (Balkema, Rotterdam, 1995)

[8] L.C. van Rijn, J. Hydraulic Engineering, 110(12), 1733-1754 (1984)

[9] M.F. Karim, J.F. Kennedy, J. Hydraulic Engineering, 113(2), 159-178 (1987)

[10] N.K. Raphelt, Guidance on the selection and use of sediment discharge formulas, Proc. of Hydraulic Engineering, 199-293, H.H. Chang, J.C. Hill, eds. (Proc. National ASCE Conference, San Diego CA, 1990)

[11] S.V. Alonso, Selecting a formula to estimate sediment transport capacity in nonvegetated channels. USDA Report No. 26(5), 426-439, W.G. Knisel, ed. (US Dept. of Agriculture, Washington DC, 1980)

[12] C.T. Yang, Incipient motion and sediment transport, J. Hydraulics Division ASCE 99(HY10), 1679-1703 (1973)

[13] C.T. Yang, Sediment transport and unit stream power, Civil engineering practice 5(8), 265-289, P.N. Cheremisinoff, S.L. Cheng, eds. (Technomic Publishing Co., Lancaster PA, 1988)

[14] W.H. Graf, M.S. Altinakar, Hydraulique fluviale 2: Ecoulement non permanent et phénomènes de transport (Presses Polytechniques et Universitaires Romandes, Lausanne, 1996)

[15] E. Meyer-Peter, R. Müller, Formulas for bed-load transport (Proc. $2^{\text {nd }}$ IAHR Congress, Stockholm, 39-64. IAHR, Delft NL, 1948)

[16] H.A. Einstein, The bed-load function for sediment transportation in open channel flows (Soil Conservation Service, Technical Bulletin No. 1026. US Department of Agriculture, Washington DC, 1950)

[17] W.R. White, H. Milli, A. Crabbe, Sediment transport. An appraisal of available methods (Report INT 119, Hydraulic Research Station, Wallingford UK, 1973)

[18] M.H. Garcia, ed., Sedimentation engineering (ASCE, Reston VA, 2008)

[19] P.Y. Julien, Erosion and sedimentation, $2^{\text {nd }}$ ed. (Cambridge University Press, Cambridge UK, 2010)

[20] N. Chien, The present status of research on sediment transport, Trans. ASCE 121, 833$868,1956)$

[21] C.B. Brown, Sediment transportation, Engineering hydraulics, 769-857, H. Rouse, ed. (Wiley, New York, 1950)

[22] S. Dey, Fluvial hydrodynamics: Hydrodynamic and sediment transport phenomena. (Springer, Berlin, 2014)

[23] C. Ancey, T. Böhm, M. Jodeau, P. Frey, Statistical description of sediment transport experiments, Physical Review E 74, 011302 (2006)

[24] A. Recking, P. Frey, A. Paquier, P. Belleudy, An experimental investigation of mechanisms involved in bed load sheet production and migration. J. Geophysical Research, 114, F03010, doi:10.1029/2008JF000990 (2009) 
[25] F. Charru, H. Mouilleron, O. Eiff, Erosion and deposition of particles on a bed sheared by a viscous flow, J. Fluid Mechanics, 519, 55-80 (2004)

[26] F. Charru, Selection of the ripple length on a granular bed sheared by a liquid flow, Physics of Fluids, 18(12), 121508 (2006)

[27] E. Lajeunesse, L. Malverti, F. Charru, Bed load transport in turbulent flow at the grain scale: Experiments and modeling, J. Geophysical Research, 115, F04001 (2010)

[28] D.J. Furbish, P.K. Haff, J.C. Roseberry, M.W. Schmeekle, A probabilistic description of bed load sediment flux: 1. Theory. J. Geophysical Research, Earth Surface, 117(F3), F03031 (2012)

[29] G. Seizilles, E., Lajeunesse, O. Devauchelle, M. Bak, Cross-stream diffusion in bedload transport, Physics of Fluids, 26(1), 013302 (2014) 